\title{
XLVI. On the mutual solubilities of diethylamine and water
}

\section{Robert Tabor Lattey B.A.}

To cite this article: Robert Tabor Lattey B.A. (1905) XLVI. On the mutual solubilities of diethylamine and water, Philosophical Magazine Series 6, 10:57, 397-399, DOI: $10.1080 / 14786440509463385$

To link to this article: http://dx.doi.org/10.1080/14786440509463385

央 Published online: 16 Apr 2009.

Submit your article to this journal \lceil

Џ Article views: 5

Q View related articles $\sqsubset$ 


\section{[ 397 ]}

XLVI. On the Mutual Solubilities of Diethylamine and Water. By Robert Tabor Lattey, B.A.*

DAIRS of liquids which exhibit partial miscibility are usually divided into three classes:-(1) Those which are completely miscible above a certain temperature and only partially miscible at lower temperatures; (2) Those which are only partially miscible at all observed temperatures; and (3) Those which are completely miscible below a certain temperature above which they become partially miscible.

The only cases of the third class which have been at all fully studied are: sym-trimethylpyridine and water, triethylamine and water (Rothmund, Keit. Phys. Chem. xxvi. p. 433, 1898), diethylamine and water (Guthrie, Phil. Mag. xviii. p. 500, 1884) $t$.

The case of nicotine and water recently studied by Hudson (Zeit. Phys. Chem. xlvii. p. 113, 1904) forms an interesting combination of cases (1) and (3) since these liquids are completely miscible below $64^{\circ}$ or above $205^{\circ}$, but between these temperatures their mutual solubilities are only partial ; the solubility-temperature curve representing these phenomena is a closed elliptical figure.

This work was originally undertaken with the idea of extending Guthrie's curve showing the relation between temperature and the miscibility of diethylamine and water. It was soon found that either Guthrie's results were incorrect or that some unexpected influence was raising the temperature of separation. The results obtained at first were not only in disagreement with Guthrie's, but were not in concordance with one another. At length the behaviour of one of the tubes (which happened to contain 58.6 per cent. of the amine) furnished a clue to the difficulty; the contents of this tube separated into two layers at $140^{\circ} \cdot 2$, after being cooled to about $130^{\circ}$ and mixed they separated at $138^{\circ}$; a second and third repetition of the observation gave $137^{\circ}$ and $135^{\circ}$ respectively. Obviously some change was taking place in the contents of the tube: this might either be due to an action of water on diethylamine at high temperature or to the solution of glass. Experiment showed that about $1 \mathrm{mgrm}$. of solid had been taken up by the liquid. Experiments were therefore begun in tubes of Jena glass; the results so obtained were concordant, and measurements made on individual tubes did not differ from one another more than observations of a meltingpoint usually differ.

* Communicated by the Author.

† The case of dimethylamine and water, given by Prof. van't Hoff in his "Lectures on Theoretical and Physical Chemistry," is a misprint. (Private communication.)

Phil. Mag. S. 6. Vol. 10. No. 57. Sept. 1905. 2 E 
The results obtained were as follows :-

\begin{tabular}{|c|c|c|c|}
\hline Per cent. amine. & $\begin{array}{c}\text { Temperature of } \\
\text { separation. }\end{array}$ & Per cent. amine. & $\begin{array}{c}\text { Temperature of } \\
\text { separation. }\end{array}$ \\
\hline $\begin{array}{l}21 \cdot 73 \\
22 \cdot 65 \\
25 \cdot 04 \\
25 \cdot 06 \\
28 \cdot 60 \\
30 \cdot 93 \\
34 \cdot 03 \\
38 \cdot 18\end{array}$ & $\begin{array}{l}154 \cdot 5 \\
151 \cdot 7 \\
147 \cdot 5 \\
147 \\
144 \cdot 4 \\
144 \\
143 \cdot 2 \\
143 \cdot 5\end{array}$ & $\begin{array}{l}39 \cdot 63 \\
45 \cdot 78 \\
48 \cdot 89 \\
51 \cdot 71 \\
54 \cdot 24 \\
54 \cdot 78 \\
58 \cdot 59 \\
58 \cdot 99\end{array}$ & $\begin{array}{l}143^{\circ} \cdot 5 \\
144 \cdot 15 \\
145 \\
146 \cdot 8 \\
148 \cdot 5 \\
150 \cdot 3 \\
152 \cdot 3 \\
156\end{array}$ \\
\hline
\end{tabular}

The "critical" temperature so found is $143^{\circ} .5$ and the "critical" concentration $37 \cdot 4$ per cent. of amine; whereas Guthrie's results lead to $121^{\circ}$ and 19 per cent. respectively. That this divergence is attributable to the glass seems not

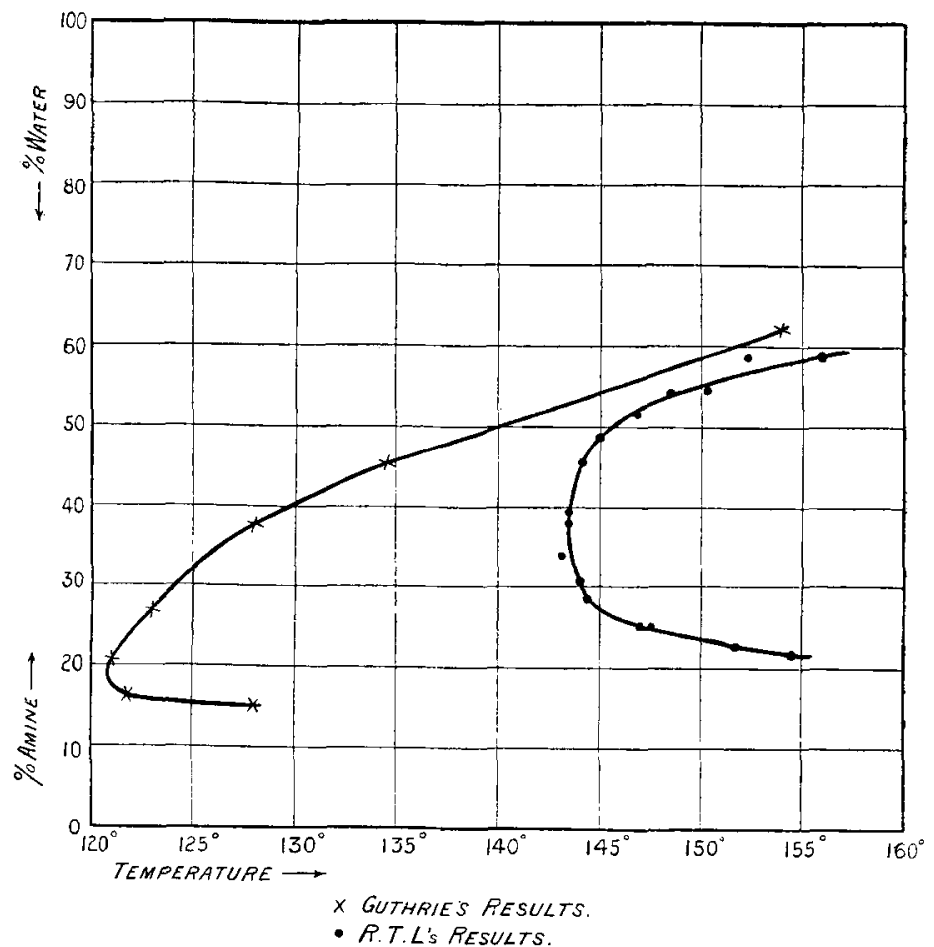

unreasunable when we read Guthrie's statement that "the 62.35-per-cent. solution caused the surface of the glass (soft 
German) to peal off in visible scales when heated to $150^{\circ}$ $160^{\circ} . "$

An experiment with Müller's new "Resistance" glass showed that even the slightly greater solubility of this giass as compared with Jeni giass caused a lowering of the temperature of over $2^{\circ}$.

It seems therefore probable that the present results are slightly vitiated by the solution of glass, but the extreme insolubility of Jena glass makes it likely that the inaccuracy due to its solution is but slight.

It is interesting to note that the form of the curve is more that of the curve for trimethylpyridine (Rothmund, Zeit. Phys. ('hem. xxvi. p. 462, 1898) than of that for triethylamine (ibid. p. 461).

An attempt was made to determine the densities of saturated solutions of the amine and water at various temperatures by heating a solution containing 40.5 per cent. of amine in a graduated tube and observing the volumes of the layers at various temperatures; the weights of the layers being calculated from the percentage composition of the saturated solutions as read off from the solubility curve. The attempt proved abortive since the values obtained are so largely affected by small errors in the data used ; it was, however, obvious that there is (1) practically no sudden change in total volume on separation, and (2) very little difference in the densities of the two saturated solutions which are in equilibrium at temperatures between $143^{\circ} .5$ and $153^{\circ}$.

\section{Experimental Details.}

Suitable quantities of water and diethylamine were weighed out from "weighing pipettes" into a small stoppered bottle. The mixture so made was transferred as soon as possible to a tube sealed at one end and drawn to a capillary in the middle; by changes of pressure the liquid was got into the lower part of the tube, which was then sealed off at the capillary.

A tube so prepared was heated in a paraffin bath so arranged that the filament of an incandescent electric lamp could be viewed through the tube. The appearance of a fog was very easily seen in this way, and consequently the temperature at which the mixture under observation separated into two layers could be ascertained with a fair degree of accuracy. The tube was supported by a simple mechanical device whereby the contents could be remixed between observations without removing the tube from the bath.

Oxford, May 1905 . 